\title{
Modelos de determinação social das doenças crônicas não-transmissíveis
}

\author{
Models of social determination \\ of chronic non-communicable diseases
}

Naomar Almeida-Filho 1

\footnotetext{
1 Instituto de Saúde Coletiva da Universidade Federal da Bahia.

Rua Padre Feijó 29/40 andar, Campus Canela, 40210-

070, Salvador BA.

naomar@ufba.br
}

\begin{abstract}
This essay critically revises theoretical frameworks and models of social determination of chronic non-communicable diseases. Functionalist sociology generated sociocultural models of health that influenced the field of epidemiologic investigation of so-called "new morbidity" (basically chronic and degenerative illnesses), later contained under the generic label of stress theory. $\mathrm{Neo}$-durkheimian approaches of social inequalities, based on the social capital concept, are analyzed and theoretical uses of the lifestyle notion in the health field are criticized. Models derived from the dialectical materialism, grounded on the concepts of labor and social class, are also discussed as they have turned quite influential in Latin-American social epidemiology. Finally, considering theoretical and conceptual gaps of such partial theories in what concerns the symbolic space of the social life, the conceptual bases of an alternative theoretical focus: the theory of mode of life and health. As a possible synthesis of the models object of this critical review, it is considered as especially suitable for the elaboration of epidemiologic models of social determination of non-transmissible chronic diseases.
\end{abstract}

Key words Chronic diseases, Social determination, Stress, M ode of life, Health inequities
Resumo Este ensaio revisa criticamente marcos referenciais e model os teóricos de determinação social das chamadas Doenças Crônicas NãoTransmissíveis. A sociologia funcionalista gerou model os socioculturais de saúde que influenciaram o campo de investigação epidemiológica da chamada "nova morbidade" (basicamente enfermidades crônicas e degenerativas), posteriormente agrupados sob o rótulo genérico de Teoria do Estresse. Analisam-se abordagens neodurkheimianas das desigualdades sociais, baseadas no conceito de capital social, criticando especialmente os usos quase-teóricos da noção de "estilo de vida" no campo da saúde. Discutem-se ainda alguns modelos derivados do materialismo dialético que se tornaram bastante influentes na epidemiologia social latino-americana, com base nos conceitos de trabalho e classe social. Finalmente, considerando lacunas teóricas e conceituais dessas teorias parciais no que diz respeito ao espaço simbólico da vida social, apresentam-se as bases conceituais de um enfoque teórico alternativo - a "teoria do modo de vida esaúde". Tomada como síntese possível dos model os objeto desta revisão crítica, considera-se esta teoria como especialmente indicada para a elaboração de model os epidemiológicos de determinação social de doenças crônicas nãotransmissíveis.

Palavras-chave D oenças crônicas, Determinação social, Estresse, M odo de vida, I niqüidades em saúde 


\section{Introdução}

O objetivo deste texto é revisar criticamente abordagens correntes (marcos referenciais emodelos teóricos) do processo de determinação social das chamadas Doenças Crônicas N ão-Transmissíveis, focal izando os principais modelos explicativos e seus respectivos marcos teóricos. 0 marco teórico da sociologia funcionalista propiciou a estruturação de modelos psicossociais de saúde, posteriormente agrupados sob o rótulo genérico de Teoria do Estresse que influenciaram o nascente campo de investigação epidemiológica. Incluiremos nesteitem as atuais abordagens neodurkheimianas das desigualdades sociais e as teorias do capital social em saúde, criticando especialmente os usos quase teóricos da noção de "estilo de vida". Em segundo lugar, discutiremos al guns modelos derivados do materialismo dialético que se tornaram bastante influentes na epidemiologia social latino-americana, em especial aqueles baseados nos conceitoschave do marxismo clássico: processo de trabaIho e estrutura de classes da sociedade.

A partir dessa análise crítica, avaliaremos as lacunas teóricas e conceituais dessas teorias parciais no que diz respeito aos domínios fundamentais da vida social: o simbólico e a cotidianidade. Para dar conta dessas lacunas, mais re centemente tem se proposto uma terceira abordagem social da saúde que se pode chamar de "epidemiologia do modo de vida", conforme pretendemos esboçar em A ciência da saúde (AImeida Filho, 2000).

As referências a essa linha teórica têm sido até agora tímidas e fugazes, sendo já tempo de se buscar uma sistematização, mesmo que inicial, dos elementos fundamentais dessa proposta. Esteé justamente o conteúdo da parte final deste texto, onde pretendemos inicialmente demonstrar que o conceito "modo de vida" se articula organicamente ao arcabouço inacabado da teoria social marxista, tendo sido desde o início utilizado (mas não suficientemente elaborado) para enfocar as práticas sociais cotidianas. Em seguida, apresentaremos algumas tentativas precursoras e embrionárias de utilização desta categoria para a construção teórica no campo da saúde coletiva, além de propostas de teorização paral elas à abordagem do modo de vida e saúde, com base em conceitos análogos ou equivalentes como "signos, significados e práticas de saúde" e "práticas de saúde". Em conclusão, a partir da síntese de al guns elementos dos model os objeto desta revisão crítica e mediante articulação dos três circuitos dialéticos fundamentais para a compreensão do processo saúde-enfermidade em sociedades concretas: 0 trabal ho, a reprodução social e o modo de vida, apresentamos as bases conceituais de um enfoque teórico alternativo - a "teoria do modo de vida e saúde" - especialmente adequado para a elaboração de modelos epidemiológicos de determinação social das Doenças Crônicas Não-Transmissíveis.

\section{Model os da epidemiologia social norte-americana}

Na segunda metade do século 20, macroteorias de desenvolvimento econômico dominaram o cenário científico latino-americano, reforçando uma abordagem da saúde fundamentalmente como insumo para a formação do chamado capital humano. A medicina preventiva, originalmente constituída como solução ideológica para a crise estrutural do sistema de saúde norte-americano, apresentava-se então como projeto de transformação da realidade sanitária da América Latina através da reforma pedagógica do ensino médico (Arouca, 1975). D ata desta época a introdução do ensino da epidemiologia no continente como uma das disciplinas básicas capazes de orientar uma atitude preventiva diante dos agravos e problemas de saúde.

Nas décadas de 1960 e 1970, ocorreu um grande esforço de construção teórica na área da saúde, desafiada pelo aumento relativo da chamada "nova morbidade", constituída basicamente por enfermidades crônicas e degenerativas (Gonçalves, 1990). Podemos citar principalmente os trabalhos de Ruel Stallones e RenéDubos, buscando a elaboração de model os ecológicos de saúde-enfermidade especialmente focados em doenças transmissíveis, e as contribuições de John Cassel e Leonard Syme, entre outros, no sentido de uma epidemiologia social das D oenças Crônicas Não-Transmissíveis no quadro de referência do funcionalismo sociológico norte-americano. Analisaremos, em primeiro lugar, os modelos teóricos diretamente articulados a este referencial. Dentre esses modelos, destacam-se a "teoria do estresse" (Selye, 1956; Cassel, 1974) e a "teoria da mudança cultural em saúde" (Barger, 1977). A pesar de articuladas em seus conceitos fundamentais, trata-se de abordagens bastante distintas - enquanto a teoria do estresse opera no âmbito microssocial das relações interpessoais, o outro enfoque ou conjunto 
de hipóteses sobre as conseqüências das transformações sociais sobre a saúde se refere ao nível macrossocial das sociedades e das culturas.

A teoria do estresse deriva diretamente de investigações com animais, tendo sido formulada em suas condi ções atuais através dos trabaIhos de Cannon e Selye, na década de 1930. De acordo com o trabalho sistematizador de Cassel $(1974,1976)$, para esta teoria, processos de origem social atuam principalmente como estressores não-específicos, aumentando a suscetibilidade de certos organismos diante de um estímulo nocivo direto (o agente), mediante alterações do sistema neuroendócrino. A teoria do estresse também admite a determinação constitucional de morbidade desencadeada por fatores biológicos e ambientais, o que inclui doenças infecciosas e parasitárias. Os quadros clínicos derivados de tal processo não seriam manifestações específicas de um tipo peculiar de estressor social, mas sim do agente microbiano ou físico-químico ou da base genética à qual o organismo estava exposto. Para os pioneiros desta teoria, enquanto os agentes de doença exercem um efeito patogênico direto e unívoco, danificando ou alterando a estrutura e função no plano tissular ou bioquímico, os estressores operam indiretamente (ou condicionalmente) em virtude da sua capacidade de agir na esfera simbólica (H inkle Jr., 1973).
Os estressores podem ser de natureza individual ou de natureza coletiva. 0 estressor individual pode atuar de modo agudo, com ação equivalente ao que foi designado como "eventos de vida", ou sob a forma de estresse crônico (Dohrenwend \& Dohrenwend, 1974). Os estressores coletivos ou sociais igualmente podem implicar ação aguda, como as guerras e os desastres naturais, ou ação crônica, por exemplo, o chamado "estresse social" da opressão, da miséria e das desigualdades sociais (James \& Kleinbaum, 1976).

Conforme a figura 1 , os efeitos do estresse podem ser diretos ou indiretos (Cassel, 1974, 1976). Os estressores podem diretamente determinar quadros psicopatológicos (ansiedade, depressões e somatizações), comportamentos de risco e, ainda no nível biológico, imunodepressão. Sob mediação de diferentes graus de vulnerabilidade, estressores podem indiretamente determinar desde quadros mórbidos chamados classicamente de "psicossomáticos" e as Doenças Crônicas Não-Transmissíveis, incluindo nesta lista quadros cardiovasculares (principalmente hipertensão arterial, acidentes vasculares e infarto do miocárdio), diabetes e perturbações gastrointestinais, até acidentes, suicídios, e, mediante a queda da resistência imunitária, doenças infectocontagiosas e neoplasias.

\section{Figura 1}

M odelo teórico do estresse de Cassel.

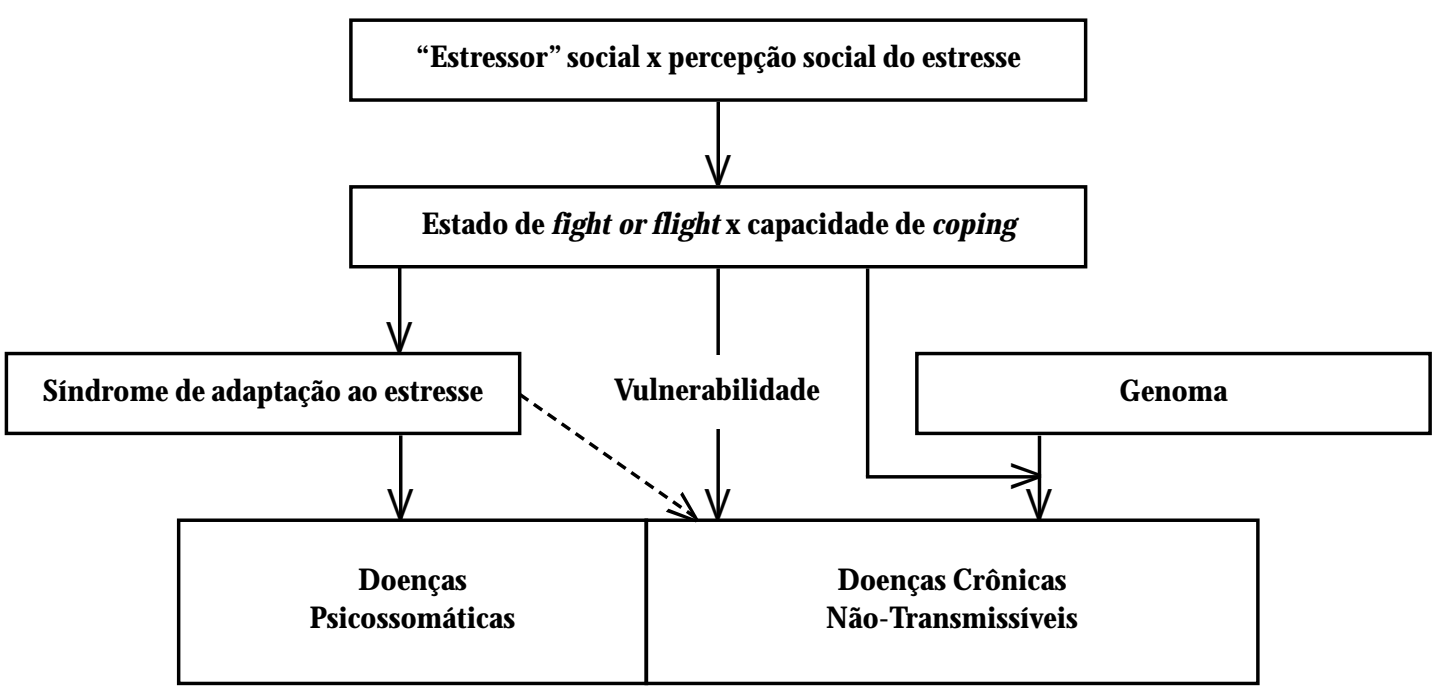


Para esta teoria, os estressores não diferem em essência dos seus antagonistas, os amortecedores (buffers), distinção mais na ordem do contexto, significado e idiossincrasias dos suscetíveis. Os amortecedores ou mediadores do estresse reduziriam os efeitos nocivos agindo na vulnerabilidade dos sujeitos. Isto poderia acontecer, por um lado, com a mobilização de recursos externos, mediante fatores genericamente denominados de apoio social (Kaplan \& Cassel, 1975; Kaplan et al., 1977; Broadhead et al., 1983; Broadhead \& Kaplan, 1991), basicamente sob a forma de grupos de apoio e redes sociais. Por outro lado, 0 aumento da resistência dos sujeitos em sua capacidade para absorver ou reagir aos estressores pode ser explicada pelo uso de recursos pessoais (Kaplan, 1992), reforço da auto-estima e outras estratégias chamadas de coping behavior (Antonovsky, 1979). M erece destaque neste aspecto o trabalho de Sherman James e colaboradores que desenvolveram a teoria do active coping, baseada em elementos da cultura afro-americana, aplicando-a principalmente à investigação epidemiológica da hipertensão arterial (James, 1994).

Além de contribuir para a formulação básica da teoria do estresse, John Cassel e colaboradores, agrupados na Escola de Epidemiologia Social de Chapel Hill, propuseram aplicar este modelo à explicação das relações entre mudança social e saúde, avaliando as conseqüências para a saúde do processo social fundamental (no seu modo de entender) por que passam as sociedades ocidentais contemporâneas, o processo de modernização (I brahim et al., 1980). Segundo essa abordagem, uma cultura popular tradicional estabelece normas de vida apropriadas à situação social de comunidades e não de sociedades complexas, embora uma cultura adaptada para a vida rural possa aumentar, em vez de diminuir, os níveis de estresse para o processo saúde/ enfermidade resultando em maior risco de D oenças C rônicas Não-Transmissíveis (Cassel et al., 1960; Tyroler \& Cassel, 1964).

A coerência básica do padrão explicativo do modelo de Cassel e colaboradores seria determinada pelas idéias de função (intraestrutural) e consistência (interestrutural, porém, no sistema social) com divergências teóricas correspondentes às noções de aculturação e adaptação (Cassel, 1967). Para estes autores, a hipótese de desorganização social não seria aplicável ao estudo das conseqüências de mudanças sociais para a saúde, porque o contexto industrial moderno simplesmente não é "desorganizado" e"se- cularizado" (... mas) sim altamente organizado em princípi os diferentes (Cassel et al., 1960). Este modelo, em suma, pretende que a modernização pode ou não levar a uma situação de incongruência cultural, dependendo da velocidade de transição e do "grau de ajustamento" entre a cultura tradicional do contexto sujeito à mudança e a nova situação social (Wilson, 1970). Tais incongruências difusas podem causar tensão excessiva na rede de relações e, portanto, estresse nos indivíduos, que pode ou não ser absorvido pelos sistemas biológicos ou psicológicos. Uma atualização desta teoria, sistematizada por D ressler (1985), enfatiza que o processo de modernização também influenciaria o conjunto de recursos econômicos, psicossociais e psicológicos, disponível para os indivíduos submetidos a processos de intensa e rápida modernização com amortecedores dos estressores ou facilitadores de estratégias de coping.

Como crítica de base, podemos dizer que esta concepção apresenta um quadro extremamente ideologizado dos contextos sociais ditos tradicionais, supostamente formados por indivíduos que compartilham formas culturais e objetivos sociais harmônicos e comuns. Além disso, tratam as sociedades como se fossem agrupamentos humanos homogêneos, na medida em que omitem as privações e carências sociais bem como as desigual dades diante do acesso a recursos econômicos. Recentemente, alguns autores (Wilkinson, 1996; Kawachi \& Berkman, 2001; Evans et al., 2001; M armot, 2001; M ackenbach, 2002) tentam recuperar 0 potencial crítico da teoria do estresse, atualizando-a como instrumento teórico fundamental para o estudo das relações entre desigualdades sociais, pobreza e saúde, particularmente no que se refere à mortalidade e morbidade por Doenças Crônicas Não-Transmissíveis.

A figura 2 apresenta de modo simplificado um modelo explicativo derivado da teoria do estresse, que tem revitalizado a atual epidemiologia social das doenças não-transmissíveis, com um foco novo em iniqüidades em saúde (Wilkinson, 1996; Evans et al., 2001; M ackenbach, 2002). Dessa forma, analisam-se as conseqüências para a saúde da distribuição desigual de renda e de acesso a ativos econômicos e recursos sociais, assumindo a forma geral de capital social (Kawachi \& Berkman, 2001), além de estudar como a disponibilidade global destes recursos influencia a situação de saúde das populações (Marmot, 2001). 
Figura 2

Modelo do capital social e desigualdades em saúde (Wilkinson, Kawachi).

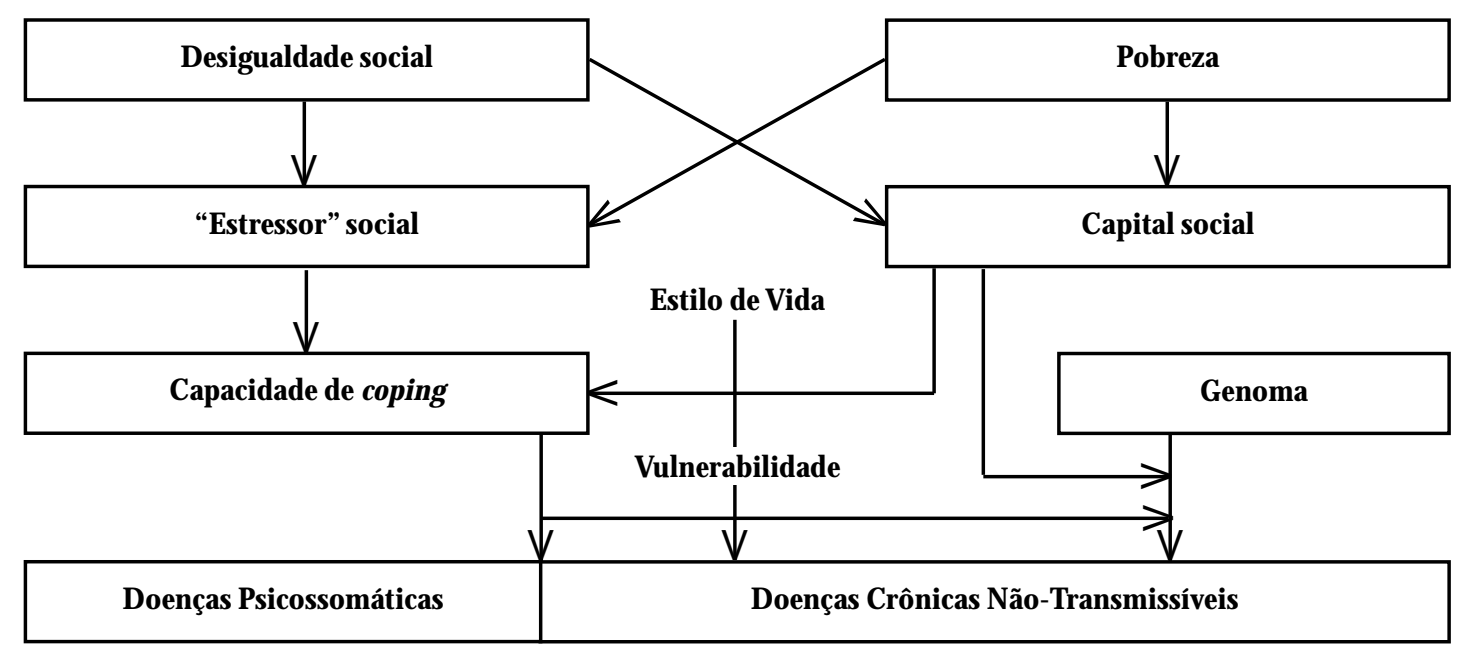

Desigual dades sociais e carências econômicas ( privação ou pobreza) são tomadas como conceitos fundamentais do modelo. 0 conceito de "capital social", de inspiração neodurkheimiana e diretamente emergente da sociologia funcionalista parsoniana (apesar de sua centralidade na teoria social de Bourdieu), aparece como importante mediador social entre os processos socioeconômicos de base, os estressores sociais e as estratégias de coping dos indivíduos. A intermediação do conceito de vulnerabilidadeé central para o modelo, tanto no que se refereà susceptibilidade diante de biopatógenos em doenças transmissíveis quanto aos determinantes genéticos da predisposição a Doenças Crônicas Não-Transmissíveis. De todo modo, ainda que introduza um importante componente social que amplia o escopo psicológico individual da teoria clássica do estresse, este modelo omite os determinantes econômicos da pobreza e privação e as raízes políticas das iniqüidades sociais.

\section{A epidemiologia social latino-americana}

O movimento da saúde coletiva, hoje hegemônico no Brasil e na América Latina, significou um contraponto às propostas de intervenção assistencialista sobre populações marginais incorporadas pelo movimento da saúde comu- nitária (Donnangelo, 1978). N este sentido crítico, em oposição aos marcos teóricos da sociologia funcionalista anglo-saxã, o campo da saúde coletiva tem definido como seu objeto o processo saúde-enfermidade não em comunidades idealizadas e harmônicas, porém no seio de sociedades complexas e contraditórias, recortadas por práticas institucionais, constituídas por agentes históricos. Nesse contexto, várias concepções críticas da epidemiologia como teoria e prática foram desenvolvidas em diferentes centros latino-americanos, abertamente destinadas a subsidiar a construção histórica do campo da saúde coletiva. Dentre as mais relevantes destas contribuições, revisaremos a "epidemiologia das classes sociais" (Breilh, 1991), e a teoria do "processo de produção e saúde" (Laurell, 1991).

A contribuição de Edmundo Granda, Jaime Breilh e colaboradores foi fundamental para a constituição de uma vertente crítica na epidemiologia latino-americana. 0 ponto de partida para a proposta teórica desses autores éa crítica aos modelos epidemiológicos convencionais, apresentados como instrumentos do projeto de dominação capitalista. N essa perspectiva, inicialmente questionam os critérios de objetividade adotados pela investigação epidemiológica, que toma os fatos de saúde-enfermidade como essencialmente "coisas biológicas". A conseqüência imediata, coerente com a natureza de 
seu ponto de partida, consiste na identificação do ponto de vista da classe operária como referencial privilegiado para a construção de um novo pensamento para a epidemiologia (Granda, 1976).

0 modelo teórico da determinação social das enfermidades elaborado pelo grupo de Quito, esquematizado na figura 3 , estrutura-se em torno de um conceito fundamental no quadro teórico do marxismo, o de reprodução social que, conforme mostraremos adiante, pode ser retomado dentro de um modelo mais praxiológico e menos estruturalista. 0 desenvolvimento das forças produtivas e das relações sociais de produção, concatenadas em modos e formas de produção, por sua vez realizados concretamente como uma formação social, determinam os padrões de reprodução simples e ampliado. Em cada um dos modos de produção que consti- tuem uma dada formação social concreta, estabelecem-se classes sociais que apresentam processos típicos de reprodução social em distintas fases do desenvolvimento das forças produtivas. De acordo com Breilh \& Granda (1985), os processos epidemiológicos se expressam concretamente em cada classe social particular por meio de um "perfil epidemiológico de classe", constituído de dois elementos: um que se refere à essência, o "perfil reprodutivo"; e outro fenomênico, o "perfil de saúde-enfermidade".

Finalmente, o processo saúde-enfermidade propriamente dito resulta da dialética entre as manifestações da reprodução social que constituem valor de uso para a classe social e aquelas que se contrapõem como nocivas ou perniciosas para a reprodução de classe (denominadas de "contra-valores"). Para Breilh (1989), o processo histórico da formação social e sua estru-

Figura 3

Modelo do perfil epidemiológico de classes de Breilh, Granda et al.

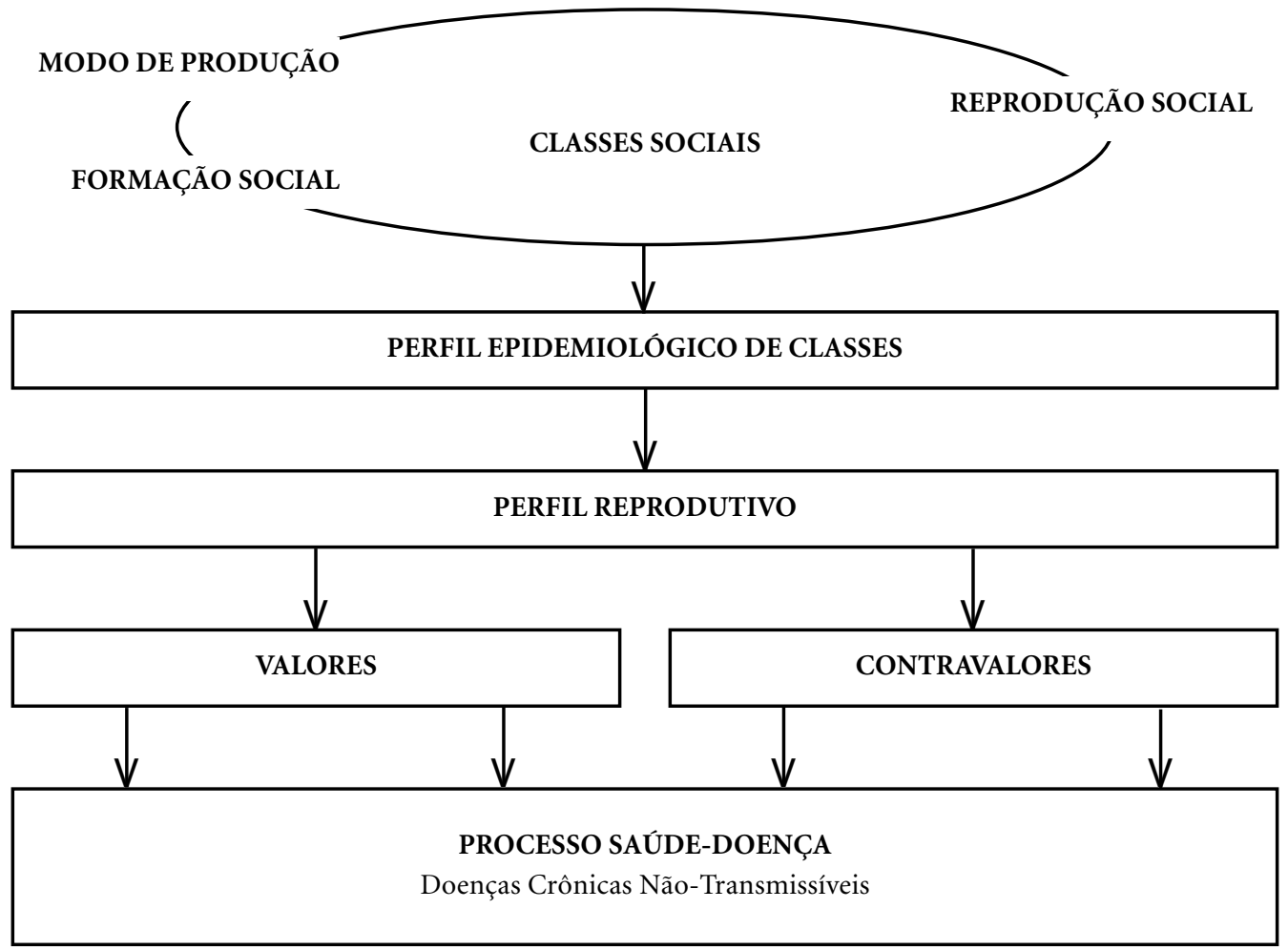


tura de classes determina qual dos pólos da contradição mais se desenvolverá. Quando o pólo da negação ou dos contravalores predomina, aumenta a enfermidade e a morte, comprometendo o perfil reprodutivo de classe; quando se intensifica o pólo dos bens ou valores de uso, potencializam-se as expressões de saúde e vitalidade da classe social. 0 modelo de Breilh não empresta destaque especial ao tema das Doenças Crônicas N ão-Transmissíveis, não obstante implicar possibilidades de acoplamento para teorias restritas de determinação desse importante grupo de morbidade.

A operacionalização metodológica desse modelo teórico tem sido tentada de duas maneiras. Vejamos a primeira: tomando-se rigorosamente a dimensão coletiva da concepção de classe social, busca-se investigar os padrões de distribuição ecológica dos indicadores de saúde, analisados por sua agregação espacial, pressupondo-se uma distribuição mais ou menos homogênea das classes no interior dos espaços social mente constituídos. A prática de investi- gação do próprio grupo de Quito aponta para esta direção (Breilh et al., 1983; Breilh, Campaña \& Granda, 1991). No que se refere à segunda maneira, epidemiólogos latino-americanos (como Mário Bronfman, César Victora e M arilisa Barros, entre outros) tentaram uma operacionalização do conceito de classe social como um atributo individual, verificando sua correspondência (e eventual redução) a categorias empíricas tais como ocupação, inserção produtiva, renda, etc., buscando construir uma certa "epidemiologia da desigualdade" (Victora et al., 1989).

De acordo com Laurell, conforme esquematizado na figura 4, só podemos entender a questão da saúde na sociedade pelo conceito de trabalho. Para isso, existem dois caminhos mais relevantes, ambos inspirados no marco teórico do marxismo. Um primeiro, proposto por García (1983), desdobra o conceito de trabalho em trabalho abstrato e trabalho concreto, buscando analisar o gasto energético e os usos específicos do corpo como produtores de atrofia-

\section{Figura 4}

M odelo do processo de trabalho de Laurell et al.

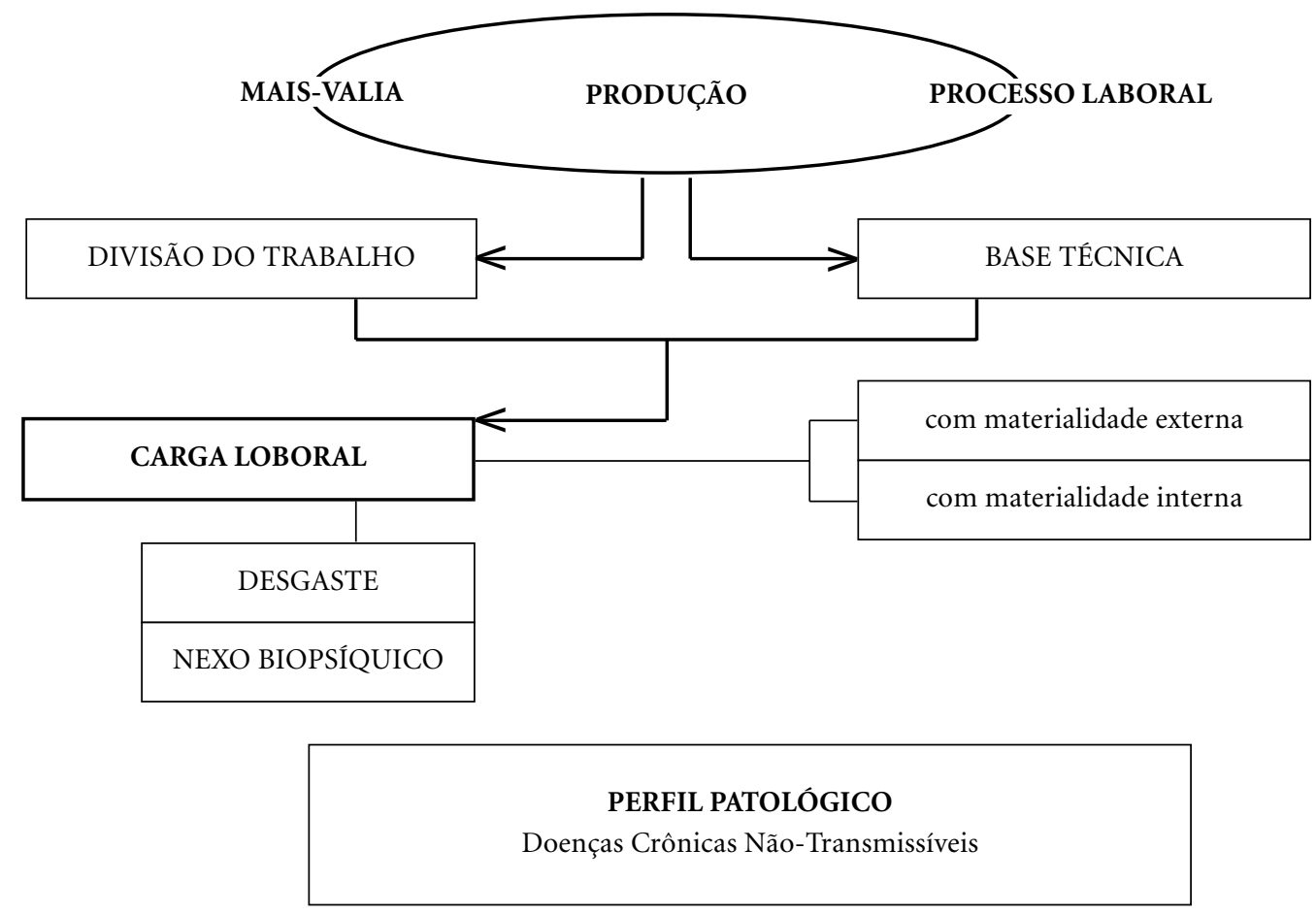


hipertrofia ou de fadiga psíquica e social. Para compreender o outro caminho, por ela escolhido, é preciso remeter-se ao conceito de processo de produção, com seus dois elementos: 0 processo de valorização (produção de maisvalia) e o processo laboral (produção de bens). Por sua vez, é necessário decompor o processo de trabalho em seus elementos constitutivos: 0 objeto e os instrumentos de trabalho e o trabaIho em si. 0 objeto do trabalho apresenta uma vertente técnica (características físicas, químicas e mecânicas) e uma vertente social, incorporando as relações sociais que o tornam possível. Os instrumentos de trabalho compreendem a materialização das relações entre capital e trabalho, incorporando igualmente a constituição tecnológica dos meios de produção. Finalmente, o conceito de trabalho em si deve ser ampliado para conter desde os processos corporais quanto à organização e divisão do trabalho como estratégia de exploração e produção de mais-valia.

No que se refere à problematização da saúde na relação saúde trabalho, em uma primeira fase, Laurell (1977) adotava o conceito de "proceso social salud-enfermedad" tal como desenvolvido pelas primeiras contribuições teóricas da medicina social latino-americana (García, 1972). Entretanto, para consolidar o seu posicionamento sem perder a congruência com a teoria do processo de trabalho, posteriormente a autora propôs substituí-lo pelo conceito de "nexo biopsíquico", identificado como a manifestação particular da corporeidade humana dos processos históricos gerais. Nesse modelo, novamente não se privilegia o importante tema das Doenças Crônicas Não-Transmissíveis, ape sar de se apontar para a determinação proximal desse grupo de morbidade com o auxílio de abordagens etiológicas restritas com as teorias do estresse.

Avançando mais no detal hamento do seu modelo teórico, Laurell toma emprestado de Tambellini (1976) a expressão "modos de andar pela vida" fazendo-a equivaler ao conceito de "estereótipos de adaptação", por sua vez importado da biologia neo-sistêmica norte-americana. Segundo ambas as autoras, tratar-se-ia de um conceito-chave originário da obra de Canguilhem. Contudo, em busca dos referenciais de base dessas importantes contribuições, não encontramos em Canguilhem a expressão "modo de andar pela vida" ou similar; refere-se a mode de vie que, apesar de implicar uma fascinante abertura teórica para lidar com as relações en- tre saúde e sociedade na esfera do cotidiano (conforme proposto adiante), nada tem a ver com o referencial do processo de trabalho e saúde.

Finalmente, Laurell considera a noção de risco insuficiente, substituindo-a pela categoria "cargas produtivas", com a distinção entre aque las "cargas com materialidade externa" (físicas, químicas, biológicas, etc.) daquelas "com materialidade interna" (ritmo, controle, tensão psíquica, etc.). Para uma representação da relação entre o processo de produção e o nexo biopsíquico, desenvolveu o conceito de "desgaste", sendo que a combinação entre desgaste e reprodução determina a constituição de formas históricas biopsíquicas específicas, substrato geral que determina uma constelação de enfermidades particulares, conhecida como o perfil patológico de um grupo social (Laurell \& N oriega, 1989).

É possível identificar alguns problemas conceituais em ambas as linhas teóricas. Em primeiro lugar, os dois enfoques assumem implicitamente uma epistemologia internalista e polarizadora, na medida em que admitem uma precedência formal efuncional do objeto sobre 0 método. Depois, e talvez em conseqüência, não conseguem escapar de uma atitude que se poderia designar como aparelhamento da investigação científica como instrumento da luta operária (Laurell) e de liberação das classes oprimidas (Breilh), o que implica uma negação da sua especificidade como modo de produção de conhecimento.

Em segundo lugar, tanto Breilh como Laurell tentam uma crítica radical ao conceito de "risco", chave para a epidemiologia contemporânea. Todavia, as noções equivalentes de "perfil epidemiológico de classe social" e de "nexo biopsíquico" são igualmente insatisfatórias. Teórica ou metodologicamente, não se mostram capazes de substituir o conceito de risco, como ferramenta conceitual para expressar o caráter coletivo do processo saúde-enfermidade. Isso é tanto mais grave na teorização de Cristina Laurell, que chega a recorrer à noção clínico-fisiológica de "perfil patológico individual".

Em terceiro lugar, na base dos seus modelos teóricos, tanto o enfoque de Breilh \& Granda quanto o de Laurell operam uma redução da complexidade social a uma única dimensão da vida social. Nesse aspecto, ambos igual mente têm lutado com veemência contra o monocausalismo, mas permanecem, por sua vez, presos a duas formas distintas de monodeterminismo: 
Breilh com a categoria de classe social e Laurell com a de processo de trabalho. M ais ainda, estabelecem entre si uma polêmica sobre a centralidade e precedência de cada uma das respectivas categorias. Nesse sentido, o próprio Breilh apresenta uma crítica radical à postulação laurelliana. Por um lado, identifica que a raiz teórica da formulação do "nexo biopsíquico" encontra-se na idéia originalmente gramsciana de "nexo psicofísico" que, no entanto, teria sido empregada de modo distorcido e inadequado. Por outro lado, aponta que o modo de apresentar a noção de "estereótipo de adaptação" permite uma interpretação reducionista do social como externo ao biopsíquico e que traz, através da categoria "adaptação" uma noção de ajuste de origem funcionalista, retomando a clássica teoria do estresse. De fato, Laurell (1981) considera que o estresse parece ser o maior risco profissional no contexto do capitalismo avançado. Em convergência com investigadores escandinavos (Gardell, 1982), analisa o estresse como resultante do aumento da complexidade do processo de funcionamento e para o incremento da produtividade, aliado ao reduzido grau de controle e autonomia dos trabalhadores no processo de produção.

Alguns cientistas de formação antropológica, como Allan Young (1980) e Gilles Bibeau (1988), há bastante tempo já questionavam as bases epistemológicas formais de tais modelos teóricos, visando construir um novo marco referencial por meio da crítica sistemática dos elementos fundamentais das teorias a serem superadas. Superando a crítica radical dos modelos de determinação social da epidemiologia latino-americana, cabe neste ponto considerar que tais teorias são rigorosas e ricas, porém parciais. E que se encontram prontas para articulação a um corpo teórico que as compatibilize entre si e as integre a outras teorias parciais sobre o que se encontra ausente de tão proveitoso e importante esforço. Trata-se dos domínios fundamentais da vida social: o simbólico e a cotidianidade. Para isso, antes precisamos apresentar a Teoria dos Signos, Significados e Práticas de Saúde.

\section{Teoria dos signos, significados e práticas de saúde}

Desde 1980, Gilles Bibeau e Ellen Corin, herdeiros da tradição transcultural de Murphy e Leighton, vêm propondo o desenvolvimento de uma antropologia crítica da saúde, capaz de superar a dicotomia cultura-sociedade e a correspondente clivagem no campo antropológico entre uma antropologia cultural (interpretativa e fenomenológica) e uma antropologia social (estrutural-funcionalista). Para esses autores, a antropologia cultural, em suas vertentes interpretativa e fenomenológica, mostra-se insuficiente para abordar a complexidade dos processos de saúde e doença e sua relação com o contexto cultural global (Bibeau, 1987; 1988; 1994; Bibeau \& Corin, 1994; 1995).

Nessa perspectiva, Bibeau, Corin e colaboradores articulam uma teoria metassintética que tem como pretensão integrar elementos semiológicos, interpretativos e pragmáticos essenciais para uma abordagem cultural da saúde (Bibeau \& Corin, 1994; Corin, 1993, 1995; Corin et al., 1989, 1990, 1993). Para esses autores, as experiências subjetivas formam-se a partir de representações culturais sobre a subjetividade, o corpo, o mundo e a vida, criadoras dos significados que se expressam através de narrativas individuais. Daí a necessidade de considerar a experiência do adoecimento e as narrativas sobre a doença em sua relação com a rede de significações culturais. Neste sentido, os autores inicialmente recorrem à concepção de rede semântica de Good que, conforme explicitam Bibeau \& Corin (1994) permite identificar os laços que unem categorias-chave culturais tanto a sistemas de interpretação quanto a histórias pessoais de indivíduos.

Isto significa estabelecer uma conexão epistemológica, teórica e metodológica entre diferentes dimensões da realidade, adotando-se uma "perspectiva global” (Bibeau, 1988). Resultante de um trabalho de articulação entre micro e macrocontextos sociais, tal perspectiva expressa uma dupla orientação que aponta, de um lado, para uma leitura historicizada e contextualizada da cultura [local] e, de outro lado, para uma interpretação das concepções que a população produz sobre os problemas de saúde mental (Corin et al., 1990). Na esfera particular da saúde-enfermidade-cuidado, trata-se de integrar sistemas semiológicos de significação e condições externas de produção (contexto econômico-político e sua determinação histórica) com a experiência do adoecimento, como transformação da identidade individual e do modo de ser-no-mundo.

Ao propor a compreensão da experiência de adoecimento a partir dessa "perspectiva global", construindo uma articulação entre trajetórias 
individuais, códigos culturais, contexto macrossocial e determinação histórica, Bibeau \& Corin introduzem, no campo da antropologia médica, a problemática da causalidade em diferentes níveis de determinação dos fenômenos (Bibeau, 1994; Bibeau \& Corin, 1994). Neste sentido, propõem um esquema analítico fundado em dois conceitos centrais: condições estruturantes e experiências organizadoras coletivas. Pretendem com estes conceitos representar os diferentes elementos contextuais (sociais e culturais) que se articulam para formar os "dispositivos patogênicos estruturais".

As condições estruturantes abrangem o macrocontexto, ou seja, as restrições ambientais, as redes de poder político e as bases de de senvolvimento econômico, as heranças históricas e as condições cotidianas de vida (ou modos de vida). Ou seja, trata-se de condicionantes referidos ao macrocontexto que atuam como elemento de modulação da cultura e como limitadoras da liberdade de ação individual. As experiências organizadoras coletivas, por sua vez, representam os elementos do universo sócio-simbólico do grupo que atuam no sentido de manter a identidade grupal, os sistemas de valores e a organização social (Bibeau, 1994; Bibeau \& Corin, 1994). Desse modo, ao postular que os sistemas semiológicos e os modos de produção articulam-se para produzir a experiência do adoecimento, os autores resgatam a pretensão de Young de considerar o contexto socioeconômico, político e histórico nos processos de saúde-doença-cuidado.

Além da influência dos fatores macrossociais, Bibeau \& Corin enfatizam a autonomia e a responsabilidade dos indivíduos na modificação da história e dos fatos sociais. A concepção médica de nosologia, segundo a qual cada signo patológico corresponde a um significado numa rede de causalidade e a procedimentos de cura-cuidado numa rede de práticas terapêuticas, não pode deixar de ser considerada, embo$\mathrm{ra}$ de forma modificada. $\mathrm{Na}$ biomedicina moderna, o sentido do sintoma é dado, portanto, pelo processo biofisiológico que lhe é subjacente eque, dessa maneira, encontra-se bloque ado ou massificado (Corin, 1993). E é justamente essa massificação/universalização do sentido que um enfoque alternativo sobre 0 complexo saúde/patologia-enfermidade-doença precisa romper.

Desta forma, Bibeau \& Corin propõem um quadro teórico de referencial antropológico, semiológico e fenomenológico para o estudo das semiologias populares e dos sistemas locais de significação e de ação diante dos transtornos mentais que pode ser apropriado para o campo das D oenças Crônicas Não-Transmissíveis. Estes sistemas enraízam-se nas dinâmicas sociaise nos val ores culturais centrais do grupo efundamentam as construções individuais da experiência de adoecimento (Bibeau, 1994; Bibeau \& Corin, 1994; Corin, 1995). Na prática metodológica, isso implica o desenvolvimento de uma "abordagem semântico-pragmática e contextual", capaz de partir de casos concretos para compreender como a comunidade percebe, interpreta e reage com relação aos problemas de saúde.

Nessa perspectiva, nas esferas de construção simbólica das comunidades, signos corporais e comportamentais são transformados em sintomas de uma dada enfermidade, adquirindo significados causais específicos e gerando determinadas reações sociais, configurando enfim 0 que Bibeau $\&$ Corin propõem denominar de "sistema de signos, significados e práticas de saúde". No geral, o conhecimento popular localmente construído é plural, fragmentado e até contraditório. A semiologia popular e os modelos culturais de interpretação não existem como um corpo de conhecimento explícito, mas são formados por um conjunto variado de elementos imaginários e simbólicos, ritualizados como racionais. Para esses autores, o conhecimento popular em torno da problemática da enfermidade se articula e se expressa em termos de sistemas semânticos construídos social e historicamente.

Dada a complexidade da realidade cultural, as diferentes interpretações dos sujeitos oriundos do centro ou da margem da sociedade refletem heterogeneidades sociais, econômicas, étnicas e culturais, bem como a realidade concreta dos diferentes atores sociais que participam das diversas situações. Isso deve ser levado em conta pelos modelos teóricos das interpretações ditas "nativas" que têm como objetivo traduzi-las para outro referencial - 0 da linguagem científica, explorando as correlações com o contexto sociocultural mais amplo. Nessa dupla perspectiva, ao mesmo tempo em que há uma submissão aos textos locais, buscando respeitar os glossários e percepções dos membros da comunidade, uma certa violência interpretativa a eles é imposta na medida em que a produção do conhecimento científico inapelavelmente tende à universalidade (Bibeau, 1988; Bibeau \& Corin, 1995). 
No cotidiano da vida das pessoas "comuns" (a comunidade para Bibeau $\&$ Corin), o processo de definição de categorias e reconhecimento dos casos de enfermidade não opera necessariamente identificando categorias nítidas de pensamento, mas por meio de semelhanças, analogias e estabelecendo uma continuidade entre os casos de acordo com uma rica e flutuante variedade de critérios. Essa categorização remete mais a modelos do tipo "protótipos de Lakoff" - resultantes de processos de family resemblance de Wittgenstein, por sua vez melhor compreendidos por sistemas alternativos de lógica (como a lógica fuzzy de Zadeh ou as lógicas paraconsistentes de Newton da Costa) - do que a uma classificação hierárquica de categorias discretas, mutuamente exclusivas e estáveis, tipificadas através de lógicas de consistência formal. Pelo contrário, as categorizações dos sistemas semânticos são fragmentadas, contraditórias, parcialmente compartilhadas e construídas localmente, organizadas em múltiplos sistemas semânticos e praxiológicos (estruturados em práticas), historicamente contextualizados e acessíveis somente através de situações concretas - eventos e comportamentos - que compõem o modo de vida das pessoas.

\section{0 conceito de modo de vida}

Originalmente, a noção de "modo de vida", ainda como conceito em estado prático, para usar a terminologia al thusseriana, encontra-se claramente explicitada nos escritos de Lewis M organ (1977[ 1877]), um dos precursores da antropologia no século passado, cuja obra inspirou Engels em seu O rigens da família, da propriedade privada e do Estado (Engels, 1972) e M arx em diversas instâncias de sua obra mestra 0 capital (Marx, 1984).

A expressão "modo de vida" foi empregada por Marx e Engels como elemento básico de análise das formações sociais pré-capitalistas, buscando particularmente situar a natureza não somente material e física da reprodução social. Em uma definição já bastante clara e elaborada, foi referido pela primeira vez na seção de abertura de A ideologia alemã ( M arx \& Engels, 1977 - grifos dos autores), da seguinte forma:

0 modo pelo qual os homens produzem seus meios de subsistência depende, antes de tudo, da natureza dos meios que eles encontram e têm de reproduzir. Este modo de produção não deve ser considerado, simplesmente, como a reprodução da existência física dos indivíduos. Trata-se, antes, de uma forma definida de atividade destes indivíduos, uma forma definida de expressarem suas vidas, um definido modo de vida deles. Assim como os indivíduos expressam suas vidas, assim eles são.

Especialmente nos Grundrisse (Marx, 1973), encontramos um aprofundamento deste conceito, às vezes referido como "condições naturais de existência" ou "modo objetivo de existência", antecipando-se de modo surpreendente ao conceito antropológico de cultura. Vejamos rapidamente alguns fragmentos dessa obra que, pela sofisticação da construção conceitual em pauta, exemplarmente dialética, não permitem evitar a longa citação:

Essas condições naturais de existência, com as quais ele [ o produtor] se relaciona mesmo como com um corpo inorgânico, têm caráter duplo: elas são (i) subjetivase (ii) objetivas. 0 produtor existe como membro de uma família, de uma tribo, um agrupamento de sua gente, etc. - o que adquire historicamente formas diversas resultantes da mistura e conflitos com outros ( $M$ arx, 1973 - grifos do autor).

$A$ atitude em relação à terra (...) significa que o homem mostra-se, desde o princípio, como algo mais que a abstração do "indivíduo que trabaIha", tendo um modo objetivo de existência (...) que antecede sua atividade e não surge como simples conseqüência dela, sendo tanto uma précondição de sua atividade, como é sua própria pele, como são os seu órgãos sensoriais (...). A mediação imediata desta atitude é a existência do indivíduo - mais ou menos naturalmente evoluída, mais ou menos historicamente desenvolvida e modificada - como membro de uma comunidade... (Marx, 1973 - grifos do autor).

A noção de "modo objetivo de existência" é definida, de maneira restrita, "como as pré condições correspondentes à individualidade" do produtor. De modo ampliado, trata-se de todas as formas em que a comunidade pressupõe os sujei tos numa unidade objetiva específica com as condições de sua produção, ou nas quais uma existência subjetiva determinada pressupõe a própria entidade comunitária como condição de produção ( $M$ arx, 1977). E finalmente, a expressão "modo de vida" é empregada para designar as "condições naturais de existência" ou o "modo objetivo de existência" das tribos pastoris nômades, funcionando como conceito de nível equivalente ao de modo de produção. Aliás, a primeira utilização do conceito, em A ideologia alemã (ver acima), obrigatoriamente remete a 
esta equivalência ao defini-lo implicitamente como "modo de produção da vida". Posteriormente, esta concepção seria formulada de maneira distinta, articulando-a com mais precisão à questão central do Capital (1984), através da referência aos "meios de vida" como elemento estruturante da reprodução social, buscando certa simetria em relação ao conceito de "meios de produção".

Pois bem, esse "al go mais", que "antecede" a atividade humana e "não surge como simples conseqüência", "naturalmente evoluído porém historicamente desenvolvido e modificado", "pré-condição" da existência humana "como a própria pele", esse "modo de vida" não será um construto de nível equivalente ao conceito antropológico de cultura? De fato, quando M arx e Engels produziram alguns escritos denominados econômico-filosóficos, entre 1845-1846, e quando Marx escreveu, em 1857-1858, as anotações que depois seriam publicadas como os Grundrisse (M arx, 1973), a ciência antropológica encontrava-se ainda na sua pré-história, naquel a fase nebulosa em que os conceitos fundamentais são objeto de definição e disputa.

Conforme comenta H obsbawn (1964), a dupla dinâmica Marx e Engels mostrava-se excepcionalmente bem informada sobre os avanços dos estudos históricos, biológicos, arqueológicos e etnográficos da época, reportando-se diretamente aos precursores da antropologia, como von M aurer, Spencer, Prescott e M organ. N essa fase, a antropologia certamente teve de produzir consensos em torno de problemas e definições, superando dilemas e controvérsias em relação à natureza do seu objetomodelo: relações de dominação e de propriedade como sugeriam o historiador von M aurer e 0 advogado M organ ou mitos, rituais e tabus como propunham os insignes catedráticos TyIor e Frazer? M organ, oriundo de uma família de comerciantes, vivera entre os iroqueses e não escondia suas simpatias pelo socialismo; Edward Burnett Tylor e Sir James Frazer eram típicos armchair scholars empenhados na consolidação do império britânico. Nenhuma surpresa, portanto, que a noção reducionista de cultura prevalecesse, pelo menos na antropologia anglo-saxã, tendo sido apresentada formalmente no capítulo "A ciência da cultura", abertura do livro Primitive culture de Tylor (1977 [1871]). Nesse sentido, a definição tyloriana, dita "clássica", efetivamente empiricista, dizia que "cultura" consiste em linguagem, costumes, instituições, códigos, instrumentos, técni- cas, conceitos, crenças, etc. de um povo (White 1978).

Da mesma forma que Engels em relação à epidemiologia, não era intenção de M arx fundar a antropologia, e muito menos se tornar catedrático de uma ciência colonial. A ironia reside no fato de que M arx, por um lado, cunhou um conceito que certamente daria densidade heurística às formulações materialistas sobre a estrutura das relações comunais, e por outro lado, conforme assinala Fabregas (1979), teria sido um dos primeiros a empregar, no volumel do Capital, dez anos antes de Tylor, o termo "cultura" no sentido moderno em oposição à "natureza". Desafortunadamente, nem M organ nem Tylor foram leitores da obra marxista.

As exigências das lutas proletárias no final do século passado e nas primeiras décadas deste século determinaram quase um monopólio teórico do conceito de classes sociais para o entendimento da dinâmica social. Somente nos anos 20, com Antonio Gramsci na Itália e Georg Lukács na Hungria, inicia-se no seio da teoria marxista uma retomada da preocupação com a dimensão do imaginário e do simbólico, aquele "algo mais" das relações sociais na vida cotidiana.

A escola italiana, representada no campo da antropologia particularmente pelo grupo de De M artino (1961), surge diretamente do pensamento gramsciano, preocupado com a questão nacional e com as culturas subalternas. Para Gramsci (1978), a análise concreta de uma conjuntura histórica e social não pode reduzir-se a um enfoque exclusivamente economicista e classista. Para compreender essa realidade sem que seja através de um modelo abstrato, é necessário incorporar outras dimensões que implicam hierarquias e heterogeneidades, como, por exemplo, as diferenças étnicas, geracionais e regionais. Assim, as questões lingüísticas, os resíduos históricos, as condutas sociais, as re des de parentesco, os rituais, as manifestações religiosas, enfim, tudo que além da economia e da política possam fazer melhor entender os processos de construção da hegemonia, passam a ser interesse primordial das análises políticas de conjuntura. Ainda na vigência de um paradigma estrutural-funcionalista na antropologia e sem notícia dos avanços teóricos da fase pré Capital da obra marxiana (dado que os M anuscritos econômico-filosóficos foram publicados somente em 1953 e os Grundrisse tiveram maior difusão somente após a edição inglesa de 1973), Gramsci se apropriou do conceito antropológi- 
co de cultura para aplicá-lo às condições concretas de existência das classes subalternas. Com isso, iniciou no seio do marxismo uma discussão sobre a cultura popular que ainda se mostra fértil e atual.

O conceito de modo de vida chegou a ser fugazmente empregado no contexto de uma "antropologia soviética", conforme definido por Kelle \& Kovalzon (1975):

El modo de vida es la esfera del consumo individual de bienes materiales y espirituales, es la esfera de la vida cotidiana fuera del tiempo de trabajo. (...) es una parte especial de la vida social, vista la necesidad que tiene cada persona de reponer sus fuerzas gastadas en el proceso de la actividad laboral.

Entretanto, a Escola de Budapeste, criada pelos herdeiros do pensamento de Lukács, será certamente mais importante para a construção conceitual que nos interessa, considerando o projeto coletivo de reintegrar as obras de juventude de Marx ao seio da filosofia política do materialismo histórico, resgatando categorias essenciais para sua atualização. A mais ilustre representante deste grupo, a filósofa magiar Agnes H eller (1929-...), em diálogo permanente com as ciências sociais contemporâneas, consistentemente desenvolve uma teoria do cotidiano, enfim abrindo perspectivas de construção de uma antropologia dialética de base nãoestruturalista. Em duas importantes de suas obras originalmente publicadas na década de 1970, Sociologia da vida cotidiana (Heller, 1977) e 0 cotidiano e a história (Heller, 1989), a filósofa apresenta reflexões sobre a cotidianidade como categoria fundamental de uma teoria microssocial marxista, analisando a determinação do modo de vida em articulação com a esfera restrita da produção econômica.

De acordo com Heller (1989), A vida cotidiana é, em grande medida, heterogênea; (...) sobretudo no que se refere ao conteúdo e à si gnificação ou importância de nossos tipos de atividade. Todavia, a significação e o conteúdo da vida cotidiana não expressam apenas uma imensa variedade de formas "de viver a vida", mas também refletem formas concretas de uma hierarquia que não é eterna e imutável, e que se modifica de modo específico em função das diferentes formações econômico-sociais. Heller (1989) assim analisa o conteúdo da vida cotidiana: São partes orgânicas da vida cotidiana: a organização do trabalho e da vida privada, os lazeres e o descanso, a atividade social sistematizada, o intercâmbio e a purificação. (...). São tra- ços característicos da vida cotidiana: o caráter momentâneo dos efeitos, a natureza efêmera das motivações e, a fixação repetitiva do ritmo, a rigidez do modo de vida (grifos da autora). Haverá, nesta esfera da cotidianidade, uma heterogeneidade hierarquizada e articulada, com base na repetição, como um modo de produzir a vida cotidiana, porém nunca como estrutura ou superestrutura.

$\mathrm{Na}$ concepção helleriana, o modo de vida não é totalmente independente da vontade dos sujeitos, na medida em que o próprio indivíduo (...) dispõe de um certo âmbito de movimento no qual pode escolher sua própria comunidade e seu próprio modo de vida no interior das possibilidades dadas ( 1989 - grifos da autora). Por outro lado, o caráter cotidiano da atividade humana é levada bastante a sério, posto que o modo de vida é reconstruído diariamente. Em suas próprias palavras (Heller, 1977):

No âmbito de uma determinada fase da vida, o conjunto das atividades cotidianas está caracterizado por uma continuidade absoluta, ou seja, tem lugar precisamente "cada dia". I sto constitui o fundamento respectivo do modo de vida dos homens em particular.

No momento atual, pós-interacionismo simbólico e sua etnometodologia, com o advento da "nova história" e depois da virada fou caultiana, observa-se um renovado interesse pelo estudo dos microprocessos sociais. No plano epistemológico, esta tendência mostra-se convergente com as novas aberturas paradigmáticas, indicando um esgotamento dos macromodelos estruturais e uma reavaliação das "grandes teorias". N esse contexto intelectual, temas como o indivíduo, a dinâmica dos pequenos grupos e a cotidianidade (em suma, o modo de produção da vida social) retornam à cena científica, com o resgate inevitável de contribuições como a da Escola de Budapeste, além de pensadores de grande densidade analítica como $\mathrm{H}$ abermas e de Certeau.

\section{Modo de vida e saúde}

Vejamos agora como, pouco a pouco, o conceito de "modo de vida" vem assumindo uma posição de destaque na construção teórica em saúde coletiva, revelando um grande potencial heurístico que poderá resultar em uma nova vertente da epidemiologia crítica.

Há quase vinte anos, ao apresentar a medicina hipocrática como precursora da integração 
entre antropologia e epidemiologia, James Trostle (1986) fez o seguinte comentário: [Naquela abordagem] as enfermidades eram discutidas como atributos de populações, com uma ênfase causal particular dirigida para o "modo de vida" dos habitantes de uma cidade. Um outro "quase fundador" desta "epidemiologia do modo de vida" foi Eduardo M enéndez, reconhecido antropólogo mexicano dedicado às questões da saúde. Em uma coletânea sobre antropologia médica, M enéndez (1990) publicou um capítulo subtitulado " $\mathrm{H}$ acia la construcción de una epidemiología sociocultural", que merece destaque aqui por dois motivos. Em primeiro lugar, analisa criticamente a assimilação do pensamento gramsciano na área da saúde como um tipo de maniqueísmo ideológico-cultural-microgrupal, dessa maneira conectando-se a uma das importantes linhas de apropriação da questão cultural pela teoria marxista, conforme apontado acima. Em segundo lugar, reconhecendo que não só $M$ arx e Engels, mas também $M$. Weber, Durkheim e uma parte da antropologia médica constituem as referências teóricas e empíricas desta produção epidemiológica, Menéndez (1990) chega a empregar as expressões “Ios 'modos' culturales e sociales de enfermar" e "las condiciones e 'modo' de vida" para referir-se a questões epidemiológicas. N otem que em ambos os casos o autor põe aspas justamente na palavra-chave "modo", sugerindo certa relutância em incorporá-la em qualquer processo explícito de conceitualização. De fato, em seguida el e introduz "estilo de vida" como conceito que trataria de unificar a base material eideológica que opera no desenvolvimento dos padecimentos, e constituiria um conceito mediador entre o nível da classe social e ou dos grupos intermediários (grupos étnicos, grupos ocupacionais, grupos de status, grupos familiares, grupos de pares, etc.) (M enéndez, 1990). Esta posição é ratificada em trabalho mais recente, em que este autor comenta que enquanto para a epidemiologia o "estilo de vida" constituiria uma variável a mais, para a antropologia tal estilo constitui uma forma global de vida da qual o ris co pode ser parte constitutiva (M enéndez, 1995 grifos nossos).

Em 1987, escrevemos uma pequena brochura sobre o tema, onde propusemos a oportunidade deste tipo de enfoque na investigação epidemiológica em saúde mental, já indicando suas fontes na obra marxiana (nos termos expostos acima) e identificando uma correspondência com a categoria analítica de "modo de produção" (Almeida Filho, 1987). Em Epidemiologia e sociedade, Cristina Possas (1989) faz referência ao conceito de "modo de vida" como ampla efundamental instância determinante dos processos saúde-enfermidade, mediada por duas dimensões intervenientes: estilo de vida e condições de vida. Para Possas, as condições de vida se referem às condições materiais necessárias à subsistência, à nutrição, convivência, saneamento, e às condições ambientais, que são feitas essencialmente pela capacidade de consumo social. 0 conceito de estilo de vida, por outro lado, remete às formas sociais e culturalmente determinadas de viver, que se expressam em condutas, tais como a prática de esportes, dieta, hábitos, consumo de tabaco eálcool. Dessa maneira, Possas (1989) buscava articular o conjunto respeitável de achados sobre a determinação dos chamados "riscos sociais" na maior parte das patologias a modelos explicativos fundados em categorias do materialismo histórico, sem comprometer a necessária consistência teórica.

No entanto, ainda fazia falta um tratamento da questão simbólica em relação ao processo saúde-enfermidade, ou seja, ao sistema de signos e significados relacionados à distribuição e percepção dos riscos e seus fatores. Samaja (1998) formula esta questão com maior precisão, aplicando-a com propriedade à problemática das relações entre método e objeto na epidemiologia, propondo-a como disciplina capacitada a lidar com as questões da saúde no âmbito da reprodução social. Segundo Samaja, não são as taxas que nos falam da saúde-enfermidade das populações, mas sua distribuição na "discursividade da vida cotidiana" dessa população (1998). Por conseguinte, ademais da distribuição diferencial dos riscos em populações, a epidemiologia terá como objeto-modelo um objeto que implica a produção de sentido, e suas variáveis deverão dar conta dessa produção ou fracasso na gênese de sentido. (...) a fonte mesma da significação parece derivar da dinamicidade das estruturas do mundo da vida (Samaja 1998 - grifos nossos).

A questão fundamental da epidemiologia do modo de vida já pode ser claramente explicitada: trata-se de problematizar a incorporação de significado e sentido ao risco, seus fatores e seus efeitos. Isto implica abrir a epidemiologia ao estudo não só das situações de saúde, mas também das representações da saúde e suas determinações, no mundo da vida, na cotidianidade, nos modos de vida, através do conceito particular de "práticas de saúde". Curiosamente, 
o tratamento conceitual deste problema mais competente e mais promissor como fundamentação para uma "teoria do modo de vida e saúde" sequer emprega a expressão "modo de vida". Trata-se da obra recente de M ário Testa, sanitarista e pensador argentino, introdutor e depois crítico do planejamento estratégico em saúde, particularmente em Saber em saúde (1997).

Como princípio analítico de base, Testa (1997) adota a perspectiva que chama de"radicalismo antropológico", como revalorização da cotidianidade das pessoas, apresentando-a em referência direta à obra de Agnes H eller, antes mencionada. Adota ainda desta autora a seguinte definição de vida cotidiana: A vida cotidiana é o conjunto de atividades que caracterizam a reprodução dos homens particulares, os quais, por sua vez, criam a possibilidade da reprodução social (Heller, 1977). É importante analisar as implicações da seleção destas (e não de outras, dentre as inúmeras) definições de cotidianidade na obra helleriana. Em primeiro lugar, devemos notar aqui a dupla referência à esfera da reprodução, tanto na dimensão da reprodução material dos sujeitos sociais quanto no sentido da reprodução das relações sociais de produção que se estabelecem entre esses sujeitos. Ou seja, o modo de vida como estruturador tanto da reprodução quanto, através desta, da produção. Em segundo lugar, trata-se de uma definição derivada do conceito de modo de vida, no sentido discutido acima. Realmente, em seguida Testa refere-se à equivalência ou paral elo entre as mudanças na vida cotidiana com as mudanças no modo de produção.

Cuidadosamente buscando construir um quadro teórico sólido e rigoroso, Testa (1997) se posiciona perante o debate H eller-Habermas em torno do conceito lukacsiano de "mundo da vida cotidiana". Nenhuma surpresa em reconhecer que, nesta polêmica, a posição de Heller é mais atraente, porque ela teria introduzido a idéia de constituição do mundo como produção, em termos materialistas, nisto equivocadamente criticada por H abermas como idealista. Isto porquea práxis (por ele definida como prática global) determina formas de prática culturais ou práticas da vida que, por sua vez, conformam uma produção: a da vida social mesma (Testa, 1997). Identifica-se aí, em estado latente, o conceito de "modo de vida" implícito no discurso "testiano", na medida em que, para a produção da vida mesma, há que existir um modo de produção desta. M ais adiante, Testa (1997) vai assinalar que ... as práticas culturais signifi- cam a produção das relações que constituem 0 fundamento da sociedade e que podemos entender como "as relações sociais de sociabilidade", nó de um dos principais debates sociopolíticos da atualidade". Em uma analogia simétrica, as relações sociais de sociabilidade articulam o modo de vida assim como as relações sociais de produção o fazem para o modo de produção.

A fim de cobrir um possível hiato entre a cotidianidade e a ação humana, Testa (1997) recorre de Bourdieu (1980) a noção de habitus, aí definida como maneira singular, predeterminada por uma estruturação das instâncias psíquicas, com que os indivíduos incorporam ações e valores do mundo e reagem com comportamentos. Para ele, trata-se de outro conceito fundamental, equivalente ao conceito de "usos", com o qual é possível entender de uma nova maneira as contradições e conflitos nos níveis individual e coletivo, ao propor uma síntese dialética dos efeitos integradores da prática da vida social. Segundo Testa, é possível identificar usos modais para sujeitos individuais e usos positivos (portadores de positividade pura, como veremos adiante) para sujeitos coletivos. Nas palavras de Testa (1997):

En base a esta concepción podemos reconstruir a noción de "usos" reinterpretándola de la siguiente manera: a contradicción es la existencia de por lo menos dos discursos - interiores a um individuo o entre grupos - que argumentan en cuanto al significado de alguna proposición (...); el conflicto no se expresa como discurso sino como acción - denuevo en el interior de un sujeto o entre distintos grupos de la sociedad - que implica el sentido de los sentimientos puestos em juego durante la misma, que pueden ser identificados mediante una lógica do sentido ( ¿existe?) que nos hará recurrir al arte de la hermenéutica para su consideración.

O programa teórico de M ário Testa gradualmente toma forma, revelando-se como projeto de uma epistemologia capaz de articular a ciência com a vida cotidiana, buscando assim dar conta de duas importantes problematizações contemporâneas sobre o tema: a dupla hermenêutica de Boaventura Santos (1989) e a arena transepistêmica de Bourdieu (1983). Nesta articulação inevitavel mente ambiciosa, entram então a objetividade, a subjetividade, a vida cotidiana, a ciência, os indivíduos, a sociedade, as teorias, as práticas, os significados, o sentido, a constituição dos sujeitos e as determinações dos objetos, estruturados de maneira a permitir entender como e por que desapare- 
cem, permanecem e conformam um todo que expande nossas capacidades de entendimento e ação sobre a realidade (Testa, 1997).

A proposta metodológica esboçada por M ário Testa, e que podemos adotar como linha de base para o programa de investigação sobre modo de vida e saúde, particularmente no capítulo referente aos model os epidemiológicos de determinação social das Doenças Crônicas Não-Transmissíveis, incorpora o repertório mais atualizado das ciências sociais contemporâneas, com um forte componente lingüísticosemiológico. Assumindo as idéias de Julia Kristeva (1969) de uma "ciência do sentido" e incorporando o instrumental heurístico da "semanálise", Testa aponta para a investigação histórica de um conjunto de fatos sociais, práticas da vida, formulações críticas, procedimentos metodológicos, dirigidos a elucidar as relações entrea língua, a fala, a escritura, os signos, as práticas semióticas, a consciência, a ideologia... (1997 - grifos nossos). Desse modo, o objeto privilegiado dessa linha de investigação seria o corpus de discursos que se transformam em textos mediante um trabalho social, no processo de construção histórica de fatos sociais no mundo da vida. 0 conjunto desses textos conforma um discurso social comum, que no referencial original da teoria do modo de vida tem um nome, chamase ideologia, suas raízes - como assinalamos com freqüência - são míticas, religiosas ou históricas (...) porém qualquer que seja seu valor de verdade, fundamentam o "saber fazer" que se encontra nas práticas cotidianas (que incluem) as que realizamos todos os dias de nossas vidas, que conformam as atividades que podemos chamar legitimamente culturais (Testa, 1997).

$\mathrm{Na}$ proposta teórica de Testa, a concepção de ideologia como conhecimento comum é chave para a construção de equivalências com o conceito antropológico de "cultura", superando seu caráter de construto estático carente de historicidade. A relação entre consciência histórica e ideologia constitui o fundamento permanente das práticas (comportamentos sociais) na vida cotidiana, que abarca tudo o que chamamos cultura técnica (a maneira com que um povo ganha a vida) e cultura sem apelido (o que se faz com a vida que se ganha) (Testa, 1997). 0 conteúdo concreto do âmbito da vida cotidiana será então dado por um conceito fundamental para a compreensão do modo de vida, queé o de "práticas da vida cotidiana", constituidora dos “múltiplos mundos da vida” (Testa 1997). Nas palavras de Testa:
Esta realidad, vida cotidiana, mundo dela vida, mundo objetivo, mundo social de la vida, para mencionar sólo algunos de los términos utilizados por diversos autores, se constituye por la relación señalada con la praxis (la producción, el trabajo, la objetivación, la acción) en lo que podría definirse como um positividad pura, donde no existen negatividades - lo cual no significa que no haya negaciones - respecto de la vida en cuanto tal (Testa, 1997).

Esta positividade nada mais é que a ideologia que aparece, na abordagem de Testa, como uma das categorias insubstituíveis da análise da cotidianidade (Testa 1977). A expressão "positividade pura", de certo modo audaciosa, pretende implicar o caráter de saber não questionado da ideologia, no papel de base conceitual do saber fazer como fundamento material das práticas culturais. Apesar da ousadia de M ário Testa ao propor, nestes tempos neoliberais, o resgate do conceito marxista de ideologia para fundar uma teoria do cotidiano, na sua formulação observamos certa timidez teórica, demasiado respeitosa do "antropologismo" helleriano. Talvez por esse motivo é que, apesar de elaborar um sofisticado repertório de conceitos bem articulados em um quadro teórico, com a noção de "modo de vida" "na ponta da língua", Testa (1997) prefere falar de um "espaço das práticas da vida cotidiana" dentro do qual aparece um "conhecimento comum". Podemos fazê-lo em seu lugar, definindo modo de vida como conjunto articulado das práticas da vida cotidiana.

Parte importante da teoria geral do modo de vida e saúde será certamente uma teoria do sujeito, presente e importante na abordagem testiana, aqui apresentada de modo esquemático. Para Testa, na cotidianidade define-se um processo de constituição que implica o conjunto das transformações do sujeito, de sujeito originário para sujeito social e de sujeito individual para sujeito coletivo. 0 sujeito coletivo éo resultado dos efeitos de estrutura e dos efeitos da prática, através dos "atos do drama" (Testa 1995), enquanto "o sujeito da vida é um sujeito ideologizado" (Testa 1997). A constituição do sujeito conforma então um ciclo de transformações: sujeito da vida >> sujeito público >> sujeito epistêmico >> sujeito avaliador. Em um primeiro momento, produz-se o sujeito epistêmico, senhor da técnica, através de um processo de objetivização do sujeito. Porém essa objetivização não completa a transformação do sujeito da vida em sujeito epistêmico; também muda a lógica, que passa de uma lógica que tem ligação 
com o sentido das coisas, característica da vida social, para uma lógica do significado das palavras, conceitos e relações, que adquirem uma precisão que carecem na vida cotidiana (Testa, 1997). Enfim, o desafio da emancipação do sujeito implica operar o processo de constituição do sujeito da prática para transformá-lo em um sujeito "pós-epistêmico".

\section{Modelo teórico de modo de vida como determinante de DCNT}

Vimos acima como a sociologia funcional ista propiciou a estruturação de modelos psicossociais de saúde, posteriormente incorporando a questão do "estilo de vida" e das desi gualdades sociais e as teorias do capital social em saúde. Avaliamos também modelos baseados em conceitos-chave do marxismo clássico: processo de trabalho e estrutura de classes da sociedade. A partir dessa análise, identificamos importantes lacunas teóricas no que diz respeito aos domínios simbólico e da cotidianidade que demandam uma alternativa conceitual que se pode chamar de "teoria do modo de vida e saúde" (Almeida Filho, 2000). Como subsídio para a construção teórica proposta, mostramos como o conceito "modo de vida" se articula à teoria social marxista e discutimos propostas de con- ceitualização análogas e paral elas à teoria do modo de vida e saúde, especialmente a "teoria dos signos, significados e práticas de saúde" de Bibeau \& Corin e a abordagem das "práticas de saúde" de Mário Testa.

Um modelo teórico da determinação social das Doenças Crônicas Não-Transmissíveis com base na relação modo de vida e saúde não se constrói pela negação das contribuições das diferentes teorias sociais da saúde. Ao contrário, devemos buscar uma incorporação dos principais elementos dos quadros teóricos aqui revisados para formar uma estrutura explicativa mais avançada. Assim, a partir da articulação dos três circuitos dialéticos fundamentais para a compreensão do processo saúde-enfermidade-atenção nas sociedades concretas ( 0 trabaIho, a reprodução social e o modo de vida) apresentamos a seguir uma síntese de elementos dos model os objeto desta revisão crítica. Isso permite lançar as bases conceituais de um enfoque teórico certamente mais adequado para a elaboração de modelos epidemiológicos de determinação social das Doenças Crônicas Não-Transmissíveis.

Assim, conforme a figura 5, mantém-se a concepção original da formação econômico social como expressão concreta do modo de produção, destacando-se os dois processos fundamentais: o processo de trabalho (ciclos de pro-

\section{Figura 5}

M odelo etnoepidemiológico (teoria do modo de vida \& saúde).

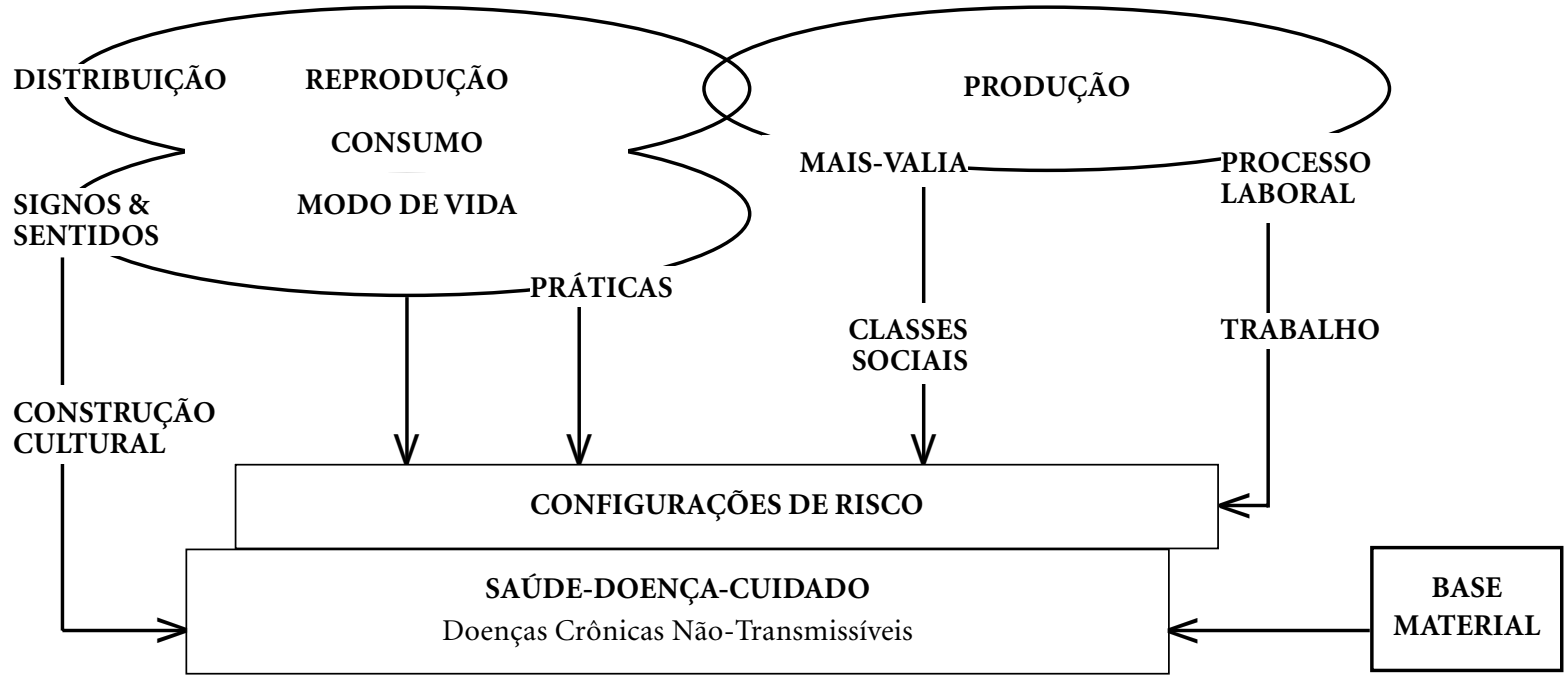


dução econômica) e o processo de reprodução social. Dessa maneira, preserva-se o papel capital da dinâmica das classes sociais e do processo de trabal ho propriamente dito como determinantes das condições de vida e, indiretamente, como condicionantes dos estilos de vida definidos conforme a formulação de Possas (1989).

0 processo da reprodução social efetivamente informa melhor a construção teórica da relação modo de vida e saúde (Samaja 2000). 0 ciclo da reprodução social (produção-distribuição-consumo), que já compartilha a interface da produção propriamente dita com o processo de trabalho, articula-se aos ciclos produtivos da vida cotidiana através do consumo, como vimos acima. As formas de produção da vida social, expressão concreta do modo de vida, também operam uma dinâmica complexa articulada aos sistemas de signos, significados e práticas expressos no modelo de Bibeau \& Corin. Trata-se, enfim, dos processos (de proteção e promoção) da saúde relacionados aos fatos sociais da vida, do crescimento, do sofrimento e da morte, ou seja, as práticas da vida cotidiana de que fala Testa (1997).

Isso significa que a análise da relação modo de vida e saúde passa necessariamente por uma semiologia e uma pragmática dos processos saúde-enfermidade-cuidado. Ambas se realizam tomando-os como efeitos de um duplo processo de construção social, tanto como produto de atos concretos de exposição-proteção a fatores e configurações de risco, efeito de estilos de vida, quanto como processos de reconhecimento e designação de anormalidade e presença de patologia, etapas prévias às respostas sociais diante dos problemas de saúde.

É nesse sentido que o conceito de modo de vida pode ser formulado como uma construção teórica basal, que não implica meramente condutas individuais ante a saúde. Tal proposição vai mais além, incluindo as dimensões sóciohistóricas, englobando a dinâmica das classes sociais e das relações sociais de produção, sempre considerando os aspectos simbólicos da vida cotidiana na sociedade. Considerando a natureza complexa, subjetiva e contextual da relação entre saúde-enfermidade e processos constituintes das iniqüidades sociais, propomos enfim substituir a clássica abordagem de fatores de risco por "modelos de vulnerabilidade", mais sensíveis às especificidades simbólicas e ao caráter interativo da relação entre os sujeitos humanos e seu meio (ambiente, cultural e sócio-histórico).

Desse modo, podemos avançar a noção de que qualquer evento ou processo social, para representar uma fonte potencial de risco para a saúde, necessita estar em ressonância com a estrutura epidemiológica dos col etivos humanos. Não se trata exclusivamente da ação externa de um elemento ambiental agressivo, conforme indicado na metáfora de fatores-produzindo-riscos, nem da reação internalizada de um hóspede susceptível, mas sim de um sistema complexo (totalizado, interativo, processual) de efeitos patológicos. A compreensão desta complexidade interativa, instável e dinâmica se revela particularmente importante para a questão científica geral dos modelos epidemiológicos de determinação social das D oenças Crônicas NãoTransmissíveis (Gonçalves, 1990).

Cremos que a referência apenas oblíqua ao conceito central de "modo de vida" na obra de M ario Testa deve-se ao fato de que o seu projeto original é eminentemente de construção epistemológica. A síntese de Testa funda-se em uma teoria das práticas sociais na cotidianidade, articulada a uma teoria do sujeito, por sua vez baseada em uma proposta metodológica derivada de teorias do sentido, do significado e da ação. Não obstante, talvez por causa da sua origem intelectual no campo da saúde coletiva, trata-se de uma perspectiva orgânica ao programa de construção de model os epidemiológicos de determinação social baseados no conceito de "modo de vida".

Em suma, a esperada e necessária teorização sobre as relações complexas entre "modo de vida" (ou práticas da vida cotidiana, na linguagem testiana) e determinantes-processo- efeitos sobre a saúde individual e coletiva nesse caso se encaixa "como uma luva" aos model os de determinação social da epidemiologia contemporânea. 0 desafio, neste momento inicial de construção teórica, será articular esse formidável dispositivo teórico, portador de uma potencialidade heurística efetivamente totalizante, à produção conceitual mais localizada no campo da Saúde Coletiva, particularmente em relação ao tema crucial das Doenças Crônicas NãoTransmissíveis. 


\section{Referências bibliográficas}

Almeida Filho N 1987. Apuntes sobre el modo de vida como determinante epidemiológico. Taller sobre Condiciones de Vida y Salud. Organização Pan-Americana da Saúde. Brasília - DF. (D ocumentos de Trabalho).

Almeida-Filho N 2000. A ciência da saúde. Hucitec, São Paulo.

Antonovsky A 1979. Health, stress and coping. Jossey-Bass, São Francisco.

Arouca AS 1975. 0 dilema preventivista: contribuição para a compreensão e crítica da medicina preventiva. Tese de doutorado. Unicamp, Campinas.

Barger W 1977. Culture change and psychosocial adjustment. American Ethnologist 4:471-95.

Bibeau G 1987. Répères pour une approche anthropologique en psychiatrie, pp. 67-76. In E Corin, S Lamarre, P M ingneault \& M Tousignant (eds.) Régards anthropologiques en psychiatrie. Editions du GIRAM E, M ontreal.

Bibeau G 1988. A step toward thick thinking: from webs of significance to connections across dimensions. M edical Anthropology Quarterly 2:402-416.

Bibeau G 1994. Hay una enfermidad en las Américas? Otro camino de la antropologia médica para nuestro tiempo, pp. 44-70. In Cultura y salud en la construcción de las Américas. Instituto Colombiano de Cultura, Bogotá.

Bibeau G \& Corin E 1994. Culturaliser l'épidémiologie psychiatrique. Les systèmes de signes, de sens et d'action en santé mentale, pp. 98-106. In P Charest, F Trudel \& Y Breton (dir.). M arc-Adélard Tremblay ou la construction de l'anthropologie québécoise. Presses de L Úniversité Laval, Quebec.

Bibeau $G \&$ Corin E 1995. From submission to the text to interpretative violence, pp. 3-54. In G Bibeau \& $E$ Corin (eds.). Beyond textuality. Ascetism and violence in anthropological interpretation. Approaches to Semiotics Series. M outon de Gruyter, Berlim.

Bourdieu P 1980. Le sens critique. Éditions de M inuit, Paris. Bourdieu P 1983. O campo científico, pp. 122-155. In R Ortiz (org.) Pierre Bourdieu. Editora Ática, São Paulo.

Breilh J 1989. Epidemiologia: economia,medicina y política. Fontamara, M éxico.

Breilh J 1991. La epidemiología (crítica) latinoamericana: análisis general del estado del arte, los debates y de safios actuales, pp. 164-214. In S Franco, E N unes, J Breilh \& AC Laurell. Debates en medicina social. OPS/ALAMES, Ecuador. (Serie Desarrollo de Recursos Humanos n. 92).

Breilh J, Granda E, Campaña A \& Betancourt O 1983. Ciudad y muerte infantil: la mortalidad infantil diferencial en el area urbana de Quito. CEAS, Quito.

Breilh J \& Granda E 1985. Os novos rumos da epidemiologia, pp. 241-253. In E Nunes (org.). As ciências sociais em saúdena América Latina. OPAS, Brasília. (Tendências e Perspectivas).

Breilh J, Campana A \& Granda E 1991. Regionalización de la calidad de vida y salud materno-infantil: aproximación a la geografia de las condiciones de salud-enfermedad en el Ecuador. Geografia Básica del Ecuador II(2):91-110.

Broadhead W \& Kaplan B 1991. Social support and the cancer patient. Cancer 67(3):794-799.

Broadhead W et al. 1983. The epidemiologic evidence for a relationship between social support and health. American Journal of Epidemiology 117(5):521-537.

Cassel J 1967. Factors involving sociocultural incongruity and change: appraisal and implications for theoretical development. M ilbank M emorial Fund Quarterly 45:41-45.

Cassel J 1974. Psychosocial processes and stress: theoretical formulation. International Journal of $\mathrm{H}$ ealth Services 4(3) 471-482

Cassel J 1976. The contribution of the social environment to host resistance. American Journal of Epidemiology 104:127-133.

Cassel J, Patrick R \& Jenkins D 1960. Epidemiological analysis of the health implications of culture change: a conceptual model. Annals of the NY Academy of Sciences 84: 938-49.

Corin E 1993. Les détours de la raison. Répères sémiologiques pour une anthropologie de la folie. Anthropologie et Sociétés 17(1-2):5-20.

Corin E 1995. The social and cultural matrix of health and disease, pp. 93-132. In RG Evans, ML Barer \& R $M$ armor (eds.). Why are some people healthy and others not? The determinants of health of populations. Aldine de Gruyter, Hawthorn, NY.

Corin E, Uchôa E, Bibeau G \& H arnois G 1989. Les atitudes dans le champ de la santé mentale. Repères théoriques et méthodologiques pour une étude ethnographique et comparative. Centre Collaborateur OMS (Centre Hospitalier Douglas), Montreal.

Corin E, Bibeau G, Laplante R \& M artin JC 1990. Comprendre pour soinger autrement. Repères pour régionaliser les services de santé mentale. Presses de L'Université de M ontréal.

Corin E, Bibeau G \& U chôa E 1993. Éléments d'une sémiologie anthropologique des troubles psychiques chez les Bambara, Soninké et Bwa du M ali. Anthropologie et Sociétés 17 (1-2): 125-156.

De Martino E 1961. La terra del rimorso. Saggiatore, Milão.

Dohrenwend B \& Dohrenwend B (eds.) 1974. Stressful life events: their natureand effects. Wiley \& Sons, Nova York

Donnangelo M CF 1978. Saúde e sociedade. Duas Cidades, São Paulo.

D ressler W 1985. Psychosomatic symptoms, stress and modernization: a model. Culture, M edicine and Psychiatry 9(3):257-288.

Engels F 1972. The origin of the family, private property and the State. International Publishers, Nova York.

Evans T, Whitehead M , Diderichsen F, Bhuiya A \& Wirth $M$ (eds.) 2001. Challenging inequities in health: from ethics to action. Oxford University Press, Nova York.

Fábregas A 1979. Antropología, marxismo y práctica política. Nueva Antropología 11:13-19.

Garcia JC 1972. La educación médica en América Latina. OPAS, Washington. (Publicación Científica 255)

Garcia JC 1983. La categoría "trabajo" en la medicina. Cuadernos M édico-Sociales 23:5-18.

Gardell B 1982. Scandinavian research on stress in working life. International Journal of H ealth Services 12:1-12.

Gonçalves RB 1990. Reflexão sobre a articulação entre a investigação epidemiológica e a prática médica: a propósito das doenças crônicas degenerativas, pp. 3985. In D Costa (org.) Epidemiologia: teoria e objeto. Hucitec-Abrasco, São Paulo-Rio de Janeiro. 
Gramsci A 1978. Concepção dialética da História. Civilização Brasileira, Rio de Janeiro.

Granda E 1976. Epidemiología: instrumento de dominación o deliberación. Universidad Central del Ecuador, Quito.

Heller A 1977. Sociologia de la vida cotidiana. Península, Barcelona.

Heller A 1989. 0 cotidiano e a História. Paz e Terra, Rio de Janeiro.

Hinkle Jr. L 1973. The concept of stress in the biological and social sciences. Science, M edicine and M an 1:34-43.

Hobsbawn E 1977. Introdução, pp.13-64. In K M arx. Formações econômicas pré- capitalistas. Paz e Terra, Rio de Janeiro.

Ibrahim M et al. 1980. The legacy of John Cassel. American Journal of Epidemiology 112(1):1-7.

James S 1994. John Henryism and the health of AfroAmericans. Culture, M edicine and Psychiatry 18(2): 163-182.

James S \& Kleinbaum D 1976. Socioecological stress and hypertension related to mortality rates in North Carolina. American Journal of Public Health 66(4): 354-358.

Kaplan B 1992. Social health and the forgiving heart. Journal of Behavioral Medicine 15(1):3-14.

Kaplan B \& Cassel J 1975. Family and health: an epidemiological approach. UNC Institute for Research and Social Science, Chapel Hill.

Kaplan B, Cassel J \& Gore S 1977. Social support and health. Medical Care 15(5): 47-58.

Kawachi I \& Berkman L 2000. Social capital. In L Berkman \& Kawachi I (eds.). Social epidemiology. Oxford University Press, Nova York.

Kelle A \& Kovalzón K 1975. Cultura y formación social. Editorial Progresso, M oscou.

KristevaJ 1968. La semiologie: science critique et/ou critique de la science, pp. 80-93. In M Foucault et al. Theorie D'ensemble. Seuil, Paris.

Laurell AC 1977. Algunos problemas teóricos y conceptuales de la epidemiología social. Revista CentroAmericana de Ciencias de la Salud 3(5):79-97.

Laurell AC 1981. Processo de trabalho e saúde. Saúde em Debate 11:8-23.

Laurell AC 1987. Para el estudio de la salud en su relación con el proceso de producción, pp. 61-94. In ALAM ES. Anales Taller Latinoamericano de M edicina Social. Medellín.

Laurell AC 1991. Trabajo y salud: estado del conocimiento, pp. 249-321. In S Franco, E Nunes, J Breilh \& Laurell AC. D ebates en medicina social. OPS/ALAMES, Ecuador. (Serie Desarrollo de Recursos Humanos $n$. 92).

Laurell AC \& Noriega M 1989. Processo de produção e saúde. Trabalho e desgaste operário. Hucitec, São Paulo.

M ackenbach JP 2002. Income inequality and population health. British M edical Journal 324:1-2.

M armot M 2001. Economic and social determinants of disease. Bulletin of the World Health Organization 79(10):906-1004.

M arx K 1973. Grundrisse - Foundations of the critique of political economy. Penguin, Londres.
Marx K 1984. 0 capital: crítica da economia política. Abril Cultural, São Paulo.

Marx K \& Engels F 1977. The german ideology. Penguin, Londres.

M arx K 1977. Economico-philosophical manuscripts. Penguin, Londres.

M enéndez E 1990. Antropología médica. Orientaciones, desigualdades y transacciones. Casa Chata/CIESAS, M éxico.

M enéndez E 1995. Antropología médica y epidemiología: proceso de convergencia o proceso de medicalización? Anais do I Congresso Latinoamericano, II Congresso I beroamericano ellI Congresso Brasileiro de Epidemiologia. Salvador, Abrasco.

M organ L 1977. La sociedad antigua [1877], pp. 65-123. In Darwin, M organ, Tylor. Los orígenes de la antropología. Centro Editor deAmérica Latina, BuenosAires.

Possas C 1989. Epidemiologia e sociedade. Heterogeneidade estrutural e saúde no Brasil. Hucitec, São Paulo.

SamajaJ 1998. Epistemologia e epidemiologia, pp. 23-36. In N Almeida-Filho, R Barata, M Barreto \& Veras R (eds). Teoria epidemiológica hoje: fundamentos, tendências, perspectivas. Fiocruz-Abrasco, Rio de Janeiro.

Samaja J 2000. A reprodução social e a saúde. Casa da Saúde, Salvador.

Santos BS 1989. Introdução a uma ciência pós-moderna. Graal, Rio de Janeiro.

Selye H 1956. Stress. Basic Books, N ova York.

Tambellini A 1976. Contribuição à análise epidemiológica dos acidentes de trânsito. Tese de doutorado. Unicamp, Campinas.

Testa M 1995. Pensamento estratégico e lógica de programação. 0 caso da saúde. Hucitec-Abrasco, São PauloRio de Janeiro.

Testa M 1997. Saber en salud - la construcción del conocimiento. Lugar Editorial, Buenos Aires.

Trostle J 1986. Anthropology and epidemiology in the twentieth century: a selective history of collaborative projects and theoretical affinities, 1920 to 1970, pp. 59-94. In C Janes, R Stall \& Gifford S (eds.). Anthropology and epidemiology: interdisciplinary approaches to the study of health and disease. Reídle, Dordrecht.

Tylor EB 1977. La ciencia de la cultura [1871], pp. 125 153. In Darwin, M organ, Tylor. Los orígenes de la antropología. Centro Editor de América Latina, Buenos Aires.

Tyroler H \& Cassel J 1964. Health consequences of culture change: II. The effect of urbanization on coronary heart mortality of rural residents. Journal of Chronic Diseases 17:167-177.

Victora C, Barros F \& Vaughan P 1989. Epidemiologia da desigualdade. Hucitec, São Paulo.

White L 1978. 0 conceito de sistemas culturais. Zahar, Rio de Janeiro.

Wilkinson RG 1996. Unhealthy societies. The afflictions of inequality. Routledge, Londres.

Wilson R 1970. The sociology of health. Random House, Nova York.

Young A 1980. The Discourse on stress and the reproduction of conventional knowledge. Social Science and M edicine 148:133-146.

Artigo apresentado em 20/4/2004

Aprovado em 10/5/2004

Versão final apresentada em 20/5/2004 